\title{
Paraganglial cells of urinary bladder and prostate: potential diagnostic problem
}

\author{
J Rode, A Bentley, C Parkinson
}

\begin{abstract}
A transurethral prostatic resection for prostatism in a 73 year old man showed a cluster of richly capillarised clear cells originally thought to be indicative of invasive carcinoma. Immunohistochemical studies were carried out on this tissue specimen and three similar cases using a variety of antibodies-Neuron specific enolase, PGP 9.5, chromogranin, synaptophysin, serotonin, somatostatin, substance $P$, calcitonin, calcitonin gene related peptide, met-enkephalin, VIP, neurofilament, CAM 5.2, S100 protein, prostatic specific antigen and prostatic acid phosphatase. The cellular foci were shown to be composed of paraganglionic cells. The cell clusters were well defined and predominantly comprised clear cells with scanty, fine eosinophilic cytoplasmic granules in three cases. The cell nuclei were round to oval, moderately pleomorphic, with evenly dispersed dense chromatin.

It is concluded that the presence of minute foci of paraganglial cells in the bladder wall and prostate gland may be misinterpreted as malignant because of their close association with nerves and their relative rarity. Immunohistochemical staining with neuroendocrine markers should dispel any doubt about their identity.
\end{abstract}

Chromaffin cells, so-called because they interact with potassium dichromate producing a brown discolouration in the solution, are found in the abdomen, the adrenal medulla, and in extra-adrenal aggregates called paraganglia. It is generally accepted that these cells are derived from the sympathetic anlage of the neural crest. The extra-adrenal chromaffin cells (paraganglia) are distributed as nonencapsulated nests in sympathetic ganglia and as encapsulated aggregates associated with prevertebral sympathetic plexus. The observations of Coupland indicate that abdominal paraganglia increase in size up to the age of 3 years after which degeneration occurs. ${ }^{1}$ The most anatomically constant paraganglion is the organ of Zuckerkandl, at the origin of the inferior mesenteric artery.

Reported observations of putative paraganglionic tissue in the bladder wall are rare. Zimmermann et al described, but did not illustrate, a focus of cells, suggestive of paraganglionic tissue found incidentally in the wall of the bladder. ${ }^{2}$ Scott and Eversole illustrated an aggregate of cells, possibly representing paraganglionic tissue. ${ }^{3}$ Such persistent paraganglionic tissue in the bladder seems to be rare; only one possible focus was found after examination of 50 total cystectomy specimens. ${ }^{4}$ Similarly, paraganglionic tissue has rarely been observed in the region of the prostate gland. We found only one reported illustration of such tissue in periprostatic tissue. ${ }^{5}$

In this report the initial paraganglion observed raised the differential diagnosis of invasive carcinoma. In this context further cases from our files were reviewed to define the morphological and immunohistochemical features.

\section{Methods}

Tissue from the index case comprised a transurethral prostatic resection for prostatism in a patient aged 73 years. A cluster of cells originally thought to represent invasive carcinoma proved negative after immunohistochemical staining for low molecular weight keratin (CAM 5.2), prostatic specific antigen (PSA), and prostatic specific acid phosphatase (PSAP). Closer examination suggested that the focus resembled paraglanglionic cells and this was confirmed by the demonstration of neuroendocrine markers.

A search through the files of the Middlesex and St Peter's Hospitals showed three similar cases (table 1).

Serial $4 \mu \mathrm{m}$ sections were taken from the routinely formalin fixed and processed material of the four cases investigated. These were stained immunohistochemically by the avidin biotin method ${ }^{6}$ for a range of poly- and monoclonal markers (table 2). Incubation with the primary antibody was usually overnight at room temperature except for the first three

Table 1 Details of four cases studied

Correspondence to: Professor J Rode,

Department of Anatomical Pathology, St Vincent's Hospital, 41 Victoria Parade, Fitzroy, Melbourne, Victoria 3065, Australia.

Accepted for publication 6 September 1989

\begin{tabular}{llllll}
\hline Case No & Sex & Age & Tissue & Clinical presentation & Pathology \\
\hline 1 & M & 73 & Prostate & Prostatism & Benign hyperplasia \\
2 & F & 20 & Bladder & Occult neuropathic bladder & $\begin{array}{l}\text { Chronic inflammation, fibrous muscle } \\
\text { replacement }\end{array}$ \\
3 & F & 75 & Bladder & No information & Epithelial hyperplasia \\
4 & M & 31 & Bladder & Frequency and dysuria & Epithelial hyperplasia and mild atypia \\
\hline
\end{tabular}


Table 2 List of antibodies used

\begin{tabular}{llll}
\hline Antibody & Clonality & Source & Dilution \\
\hline CAM 5·2 & Monoclonal antibody & ICRF & $1: 50$ \\
Prostatic specific antigen & Polyclonal antibody & Dako Ltd & $1: 5$ \\
Prostatic acid phosphatase & Monoclonal antibody & Amersham International & $1: 1$ \\
Neurone specific enolase & Polyclonal antibody & Professor R J Thompson* & $1: 2000$ \\
Protein gene product 9·5 & Polyclonal antibody & Ultraclone & $1: 2000$ \\
Neurofilament & Monoclonal antibody & Dr B Anderton† & $1: 10$ \\
S 100 protein & Polyclonal antibody & Dako Ltd & $1: 5000$ \\
Synaptophysin & Monoclonal antibody & ICN Biomedical Ltd & $1: 100$ \\
Chromogranin & Monoclonal antibody & Hybritech SA & $1: 1000$ \\
5-HT & Polyclonal antibody & Immunonuclear Corp & $1: 5000$ \\
Substance P & Polyclonal antibody & Amersham International & $1: 3000$ \\
Somatostatin & Polyclonal antibody & Dako Ltd & $1: 4000$ \\
Calcitonin & Polyclonal antibody & Dako Ltd & $1: 750$ \\
Calcitonin gene related peptide & Polyclonal antibody & Professor R Craig & $1: 500$ \\
VIP & Polyclonal antibody & Amersham International & $1: 30000$ \\
Met-enkephalin & Polyclonal antibody & Amersham International & $1: 1000$ \\
\hline
\end{tabular}

^Professor R J Thompson, Department of Clinical Biochemistry, Southampton General Hospital, Southampton; †Dr B Anderton, Department of Immunology, St George's Hospital, London; +Professor R Craig, Department of Biochemistry, University College and Middlesex School of Medicine, London.

antibodies listed which were incubated for only half hour.

\section{Results}

The paraganglionic cell islands were closely associated with the smooth muscle of the prostate gland (case 1)(fig 1a), or were found in the muscularis propria (cases 2 and 3 ) and in the deep layer of the submucosa of the urinary bladder (case 4)(fig 2). All the cell nests showed an intimate relation to nerves and blood vessels and were richly capillarised.

In sections stained with haematoxylin and eosin the cell clusters were well defined and composed predominantly of clear cells but also contained cells with scanty, fine eosinophilic cytoplasmic granules (cases 1, 2 and 3 ). In case 4 the cytoplasmic granulation was more prominent and clear cells were not seen. The cell nuclei were round to oval, moderately pleomorphic, with evenly dispersed, dense chromatin (fig la).

Immunohistochemical staining showed that all four cases were negative for the low molecular weight keratin epithelial marker

Figure 1(a)

Paraganglionic tissue found in between muscle bundles in a prostatic tissue chip. The morphological similarity to some carcinomas in this region is evident when compared with islands of bladder carcinoma depicted in fig $1(b)$.

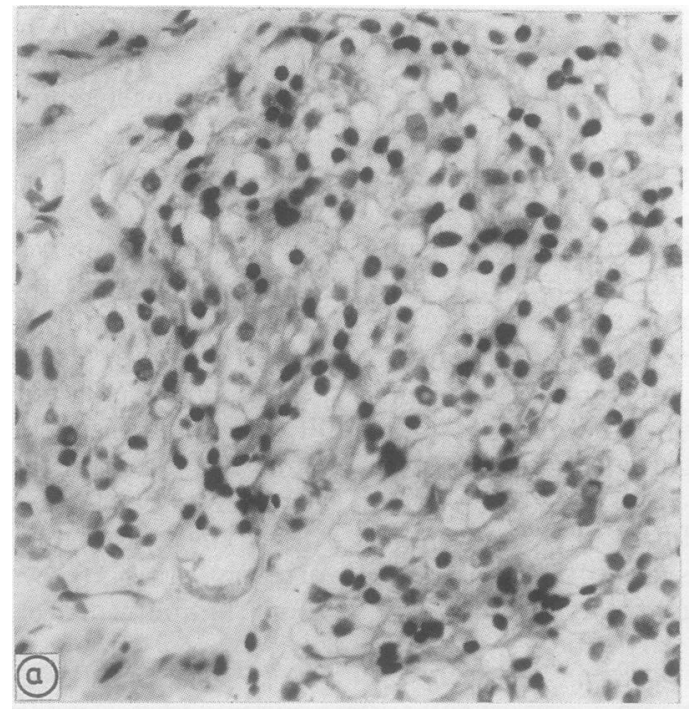

(b) Carcinoma of bladder. The carcinoma cells in this case are about double in size compared with the paraganglionic cells in fig $1(a)$. This is not evident, however, when the cases are seen in isolation. (Haematoxylin and eosin.)
CAM $5 \cdot 2$ but expressed the general neural and neuroendocrine markers NSE, PGP 9.5 and synaptophysin. They also showed strong cytoplasmic staining for chromogranin. Tests for S-100 protein were negative, and paraganglia was then diagnosed.

The tissues were stained for a range of peptide hormones and transmitter substances previously described in paraganglia and histogenetically related tumours. Only metenkephalin and VIP were expressed in all four cases. A few cells stained for 5-HT (table 3 ).

\section{Discussion}

Paraganglia have been described in the bladder and prostate. At low power our index case prompted consideration of invasive carcinoma of the prostate. In this context the relevant morphological details of paraganglia include: their circumscribed nature, vascular pattern, and cytological features. The absence of PSA, PSAP, and CAM 5.2 staining precluded prostatic and urothelial malignancy.

The true identity of these cells was confirmed by their consistently positive immuno-

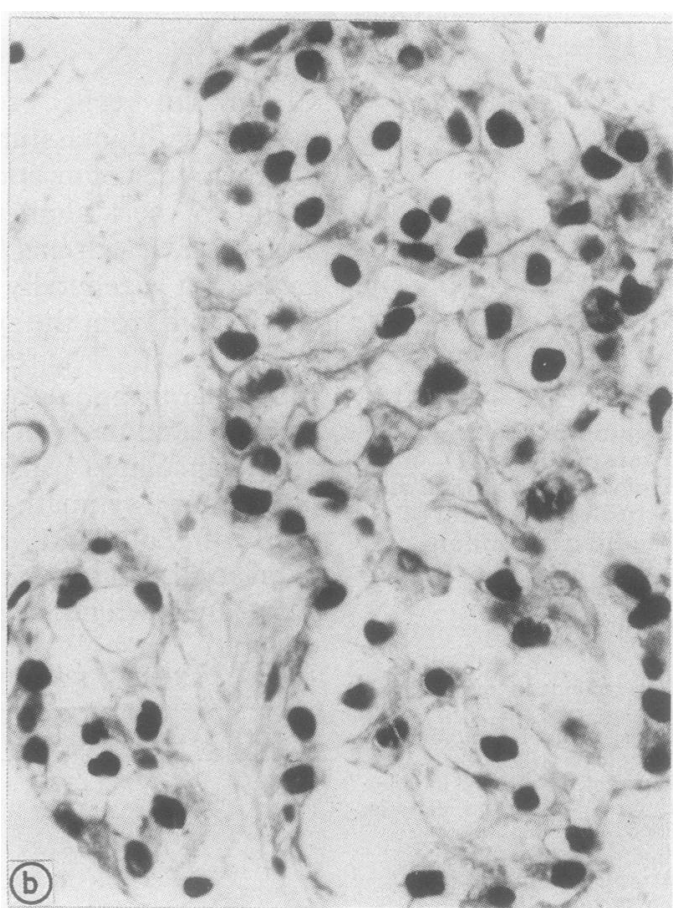




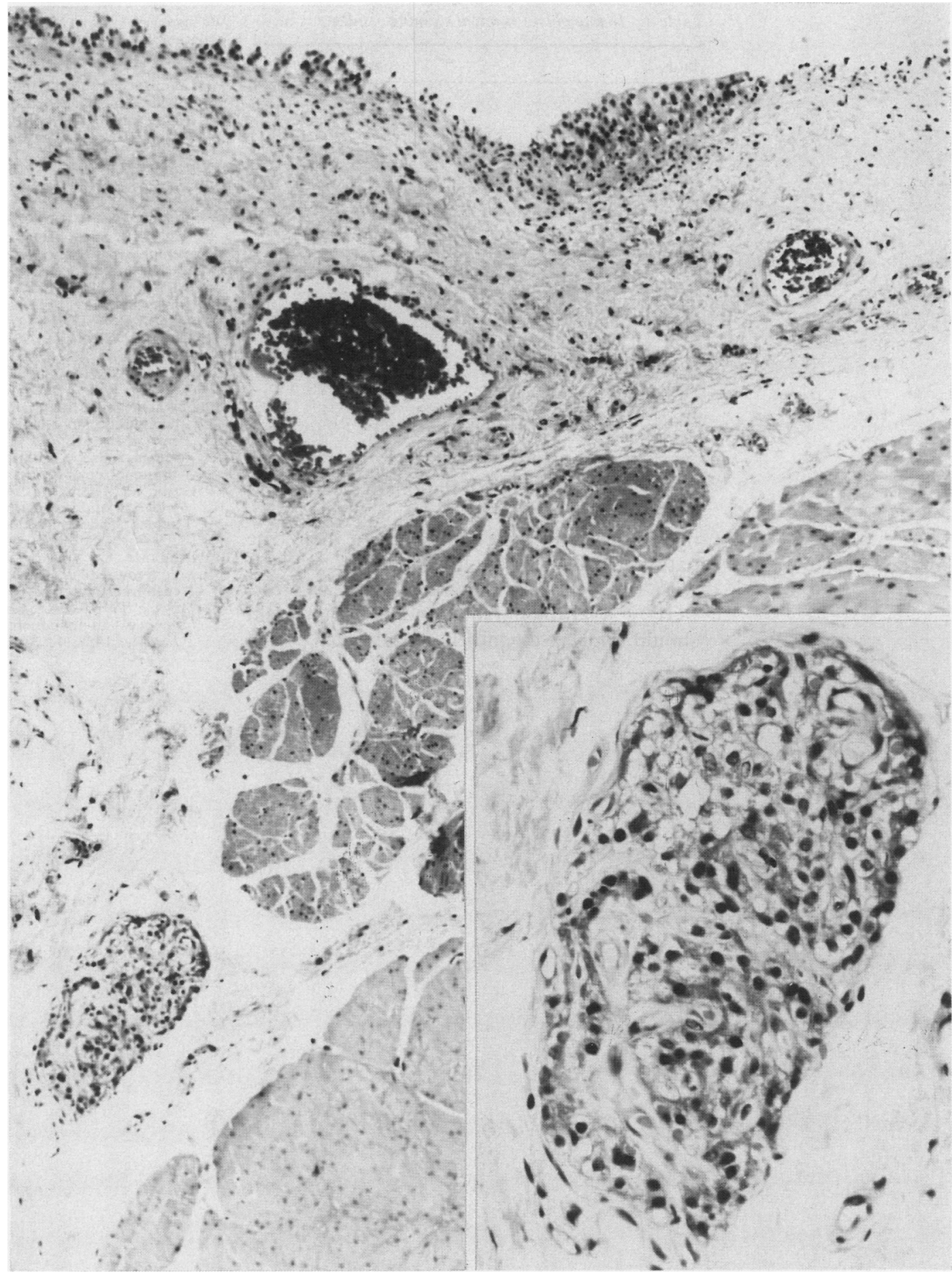

Figure 2 Low power view of urinary bladder biopsy section showing an island of paraganglionic clear cells in the deep submucosa (lower right margin). Inset shows paraganglionic tissue at higher magnification at which its characteristic vascular pattern becomes evident. (Haematoxylin and eosin.)

histochemical staining with the neuroendocrine markers neuron specific enolase (NSE), PGP 9.5, synaptophysin and chromogranin, and neuropeptide met-enkephalin. Staining with antibody against VIP was somewhat equivocal due to some non-specific "background" staining. These observations are similar to results of immunohistochemical analysis of the chromaffin cells of the adrenal medulla, where consistently positive immunohistochemical staining with NSE and metenkephalin has been reported ${ }^{78}$ and adds further weight to the evidence that the chromaffin cells of the adrenal medulla and abdominal paraganglia are of neural origin.
The paraganglia described probably give rise to true paragangliomas of bladder. ${ }^{24}$ The distribution of these neoplasms, commonly at the trigone, ${ }^{4}$ is similar to that described for autonomic ganglia in the bladder wall. ${ }^{910}$ Furthermore, the immunohistochemical features of paragangliomas ${ }^{11}$ show a strong similarity to those in the cellular clusters described above. The origin of paraganglioma from paraganglia was suggested by Zimmerman et $a l^{2}$ and Leestma and Price, ${ }^{4}$ but proof that such cells existed was rare.

In conclusion, we draw attention to the presence of minute foci of paraganglial cells in the bladder wall and prostate gland, where, 
Table 3 Immunohistochemical staining results

\begin{tabular}{ll}
\hline Antibody & Staining result \\
\hline Epithelial marker: & \\
CAM 5·2 & - \\
Prostatic markers: & \\
(Where applicable) & - \\
Prostatic specific antigen & - \\
Prostatic acid phosphatase & + \\
General neural markers: & + \\
NSE & - \\
PGP 9.5 & - \\
Neurofilament & + \\
S 100 & + \\
Synaptophysin & \\
Chromogranin & + \\
Transmitters: & - \\
5-HT & - \\
Substance P & - \\
Somatostatin & - \\
Calcitonin & + \\
Calcitonin gene related peptide & + \\
VIP & \\
Met-enkephalin & \\
\hline
\end{tabular}

because of their close relation to nerves and their apparently rare occurrence, they may be misinterpreted. Where doubt as to their true nature exists, immunohistochemical staining with neuroendocrine markers such as NSE, PGP 9.5, chromogranin and synaptophysin should improve diagnostic confidence.
We thank Miss Eileen Moss for technical and Mr D Dasandi for photographic assistance.

1 Coupland RE. Post-natal fate of the abdominal para-aortic bodies in man. $J$ Anat 1954;88:455-66.

2 Zimmerman IJ, Biron RE, McMahon HE. Pheochromocytoma of the urinary bladder. $N$ Engl J Med 1953; 249:25-6.

3 Scott WW, Eversole SL. Pheochromocytoma of the urinary bladder. J Urol 1960;83:656-64.

4 Leestma JE, Price EB. Paraganglioma of the urinary bladder. Cancer 1971;28:1063-73.

5 Srigley JR. Small-acinar pattern in the prostate gland with emphasis of atypical adenomatous hyperplasia and smallacinar carcinoma. Semin Diagnost Pathol 1988;5:254-72.

6 Bains RM, Miller KD. Peroxidase labelling in immunohistochemistry: a critical comparison of five sytems. Med Lab Sci 1988;45:240-4.

7 Lloyd RV, Shapiro B, Sisson JC, Kalff V, Thompson NW, Beierwaltes WA. An immunohistochemical study of pheochromocytomas. Arch Pathol Lab Med 1984;108:541-4.

8 Osamura RY, Tsutsumi Y, Yanaihara N, Imura $\mathrm{H}$, Watanabe K. Immunohistochemical studies for multiple enkephalin-Arg ${ }^{6}-\mathrm{Gly}^{7}-\mathrm{Leu}^{8}$, neuropepetide Y and somatostatin in human adrenal medulla and phaeosomatostatin in human adrenal medul

9 Goslin JA, Thompson SA. A neurohistochemical and histological study of peripheral autonomic neurons of the human bladder neck and prostate. Urol Int 1977;32: 269-76.

10 Schulman CC, Duarte Escalante O, Bayarsky S. The ureterovesical innervation. A new concept based on histochemical study. Br J Urol 1972;44:689-712.

11 Moyana TN, Kontozoglou T. Urinary bladder paragangliomas-an immunohistochemical study. Arch Pathol Lab Med 1988;112:70-2. 